\title{
Histórias que nossas Mães não nos Contaram: o revisionismo feminista dos contos de fadas
}

\author{
Maria Cristina Martins
}

Resumo

\begin{abstract}
No presente ensaio, discuto uma forma de escrita revisionista empregada por várias escritoras contemporâneas ao reescreverem ou relerem contos de fadas tradicionais de forma transgressora ou subversiva, a partir de uma ótica marcadamente feminista e aponto algumas das estratégias narrativas revisionistas identificadas nesse processo de revisão.
\end{abstract}

Palavras-chave: Revisão. Contos de fadas. Feminista.

Estudos contemporâneos revelam que, embora os contos de fadas, em suas mais diferentes manifestações, tenham sido celebrados como repositório de sabedoria feminina, essas histórias infantis, aparentemente inofensivas, também têm sido criticadas como inerentemente sexistas, especialmente por disseminarem falsas noções de papéis sexuais. Uma forma de escrita que tem buscado contestar distorções dessa natureza são as inúmeras releituras de contos tradicionais que vêm se multiplicando no cenário literário recentemente.

Nas últimas décadas, observa-se um crescente interesse da crítica feminista no sentido de discutir os possíveis efeitos culturais e sociais dos contos de fadas. Em The Politics of Postmodernism (1989), Linda Hutcheon chama nossa atenção para o caráter prescritivo dos contos de fadas, que direcionam as mulheres para padrões femininos de comportamentos preconcebidos:

Há uma longa tradição de literatura instrutiva cujo propósito é dizer às mulheres como "aparecer" - tornando-as mais desejáveis - aos homens [...] Mesmo os contos de fadas funcionam no sentido de passar a "sabedoria" coletiva recebida do passado e nisso refletem os mitos da sexualidade sob o domínio do patriarcado $(1989$, p. 155$){ }^{1}$

Não só os contos de fadas refletem os referidos mitos, como também podemos sugerir, observando a forma como são constituídos, transmitidos e assimilados dentro do processo de socialização, que os contos apresentam, eles próprios, traços míticos.

Roland Barthes define mito como um discurso escolhido pela história, não resultante da natureza das coisas (1972, p. 110). De acordo com ele, o mito implica a transformação da cultura em natureza ou, como ele mesmo diz, pelo menos do cultural, ideológico, histórico, em natural (1977, p. 165). Nessa perspectiva, os mitos, da forma como são construídos, acabam por esconder as motivações que se encontram 
disfarçadas sob a aparência de natural ou fatual e, tendo em vista que são determinados e construídos historicamente, é pertinente a observação de Barbara Godard a respeito do caráter temporal dos mitos: "Não há mitos eternos; eles funcionam dentro de um momento histórico e de uma prática discursiva específicos" $(1991 \text {, p. 9) })^{2}$. Assim, não nos causa surpresa que, na atualidade, haja quem se refira aos contos de fadas como "mitos contemporâneos", pois essas histórias clássicas dãonos, de fato, a impressão de que:

somos todos parte de uma comunidade universal, que partilha valores e normas [...] e que um determinado tipo de comportamento produzirá resultados garantidos, tais como vivermos felizes para sempre com muita quantidade de ouro, num maravilhoso castelo, nosso castelo e fortaleza que para sempre nos protegerá contra as forças imprevisíveis e inimigas do mundo externo. (ZIPES, 1988, p. 148)

Reconhecendo essas conotações ideológicas dos contos de fadas, várias críticas feministas, como Marcia Lieberman, Sandra M. Gilbert, Susan Gubar e Karen Rowe, salientam a necessidade de contestar e repensar as visões conservadoras de gênero e poder embutidas nessas histórias infantis:

Antes que a mulher escritora possa viajar através do espelho, rumo à autonomia literária [...] ela deve chegar a um acordo com as imagens na superfície do espelho [...] uma mulher escritora deve examinar, assimilar, e transcender as imagens extremas de "anjo" e de "monstro" que autores do sexo masculino geraram para ela (GILBERT \& GUBAR, 1979, p. 16-17). ${ }^{4}$

Assim como Gilbert e Gubar, Catherine Lappas também revela sua preocupação ao observar que "para resgatar o seu lugar na linguagem", a mulher-escritora "deve jogar com a tradição que a excluiu, com o propósito de revelar, por meio de uma divertida repetição, o seu lugar tanto dentro quanto fora da tradição" (1995, p. 12)..$^{5}$

Para confrontar imagens distorcidas como as de "monstro" e de "anjo", cristalizadas pelo discurso patriarcal, várias escritoras contemporâneas têm encontrado na revisão ou reescritura de contos de fadas tradicionais como os de Perrault, Andersen e dos irmãos Grimm, um meio eficaz de intervenção nesse discurso, transgredindo ou subvertendo noções do feminino reforçadas nessas conhecidas histórias de nossa infância.

Esse processo revisionista envolve a manipulação de convenções literárias de forma que as histórias possam ser reavaliadas a partir de uma perspectiva até então inusitada. Assim, o processo da revisão seria, como o define Adrienne Rich, "o ato de olhar para trás, de ver com novos olhos, de entrar em um texto antigo a partir de uma nova direção crítica" (1985, p. 2045). Segundo Rich, a "re-visão", no caso das mulheres, representa "mais do que um capítulo na história cultural: é um ato de sobrevivência" (1985, p. 2045) ${ }^{6}$. Como salienta Maggie Humm,

uma re-visão feminista faz um exame psíquico, cultural e histórico do passado das mulheres, e cria uma história da mulher. O conceito de Rich é próximo da noção de arqueologia de Michel Foucault - a exposição de valores morais codificados na linguagem. Rich tomou o termo da obra The Artist's View (1953) de Robert Duncan. Entretanto, onde Duncan usa "re-visão" simplesmente para descrever seu próprio passado, a re-visão de Rich é um método a ser partilhado por todas as mulheres (1999, p. 244). ${ }^{7}$

O revisionismo, portanto, dirige nossa atenção para textos do passado de modo que possamos enxergá-los a partir de novos ângulos. Para que isso seja possível, a tônica do processo revisionista é repetir uma história original, porém de um jeito diferente. Dessa maneira, 0 ato de reescrever seria, como bem observa CrunelleVanrigh, "uma ação recíproca de repetição, imitação e diferença" (2001, p. 129). ${ }^{8}$ 
No caso específico das revisões de contos de fadas tradicionais, as histórias de nossa infância chegam até nós por meio das mais diversas e inesperadas perspectivas, que vêm alterar nossa visão original. Muitos textos revisionistas transgridem ou subvertem as narrativas tradicionais, contestando significados cristalizados nas histórias, de modo que, apesar do reconhecimento das fontes ser não somente possível como também desejável, é propiciado um distanciamento crítico em relação aos textos originais, expondo, por exemplo, o caráter sexista e misógino de muitas dessas histórias. Revisões dessa natureza são, portanto, novas leituras, novas escrituras, novos exames das velhas e conhecidas "histórias da carochinha", numa atitude explícita de questionamento e desnudamento que evidencia uma recusa de conivência com a legitimação ou com a continuidade da tradição patriarcal. Como Adrienne Rich bem observa, "precisamos conhecer a escrita do passado, e conhecê-la diferentemente de como a conhecíamos; isso para não passarmos a tradição adiante, mas sim quebrarmos o seu jugo sobre nós" (1985, p. 2046). ${ }^{9}$

Para lidar com histórias herdadas, como é o caso dos contos de fadas, de forma a expor suas conotações ideológicas ou míticas, observa-se que uma das alternativas encontradas por várias escritoras tem sido "separar os usuais componentes do saber e do conhecimento e reagrupá-los em histórias anti-míticas." (ZIPES, 1988, p. 153) ${ }^{10}$. Esse processo de questionamento das histórias herdadas implica um tipo de reformulação da narrativa tradicional que propicia, entre outras coisas, a subversão de mitos culturais de feminilidade e masculinidade, a partir do próprio discurso da narrativa tradicional que, na opinião de muitos, tem funcionado como repositório de um forte sistema de interpretação disfarçado como representação.

São inúmeras as estratégias narrativas das quais se valem escritoras contemporâneas como Angela Carter, A. S. Byatt e Margaret Atwood ao reescreverem contos de fadas tradicionais, desestabilizando, de algum modo, as histórias como as conhecemos. A inversão, por exemplo, pode ser observada em textos revisionistas dessas três autoras e é empregada por elas de forma a promover a subversão de aspectos convencionais significativos dos contos de fadas reescritos. Em The Robber Bride (1993), Atwood relê o conto dos Grimm, "O noivo ladrão", invertendo o gênero do protagonista, caracterizando a personagem central da releitura - Zenia - de modo a ferir irremediavelmente a dicotomia tradicional de papéis sexuais das histórias infantis. Por mais que nos esforcemos, não há como enquadrar essa protagonista de Atwood nas categorias convencionais de vilã e heroína, de vítima e opressor(a). Em "The Djinn in the Nightingale's Eye", ao reler a história oriental do gênio da lâmpada, A. S. Byatt inverte os papéis tradicionais do conto, fazendo com que a protagonista, Gillian, conceda ao gênio a realização de seu último desejo, livrando-o de sua escravidão ao desejo dos outros. A mudança promovida por Byatt faculta ao gênio expressar seu próprio desejo e vê-lo realizado. Angela Carter, por sua vez, subverte frontalmente o consagrado desfecho do conto "A Bela e a Fera", de Madame Beaumont, principalmente no que concerne à mensagem subliminar central, que enfatiza a necessidade da supressão do lado selvagem, primitivo da sexualidade, ao inverter, em "The Tiger's Bride", o gênero de quem sofre a transformação final. $\mathrm{Na}$ releitura de Carter, a Bela é que vira Fera no desfecho da história, ficando visivelmente satisfeita com esse fato.

A mudança de ponto de vista em relação ao da história tradicional é outra estratégia narrativa de impacto revisionista. Em "The Story of the Eldest Princess" que integra a coletânea The Djinn in the Nightingale's Eye (1994) de A. S. Byatt, por exemplo, deparamo-nos com um sapo que, em hipótese alguma, aceita ser 
transformado em príncipe, como ocorre na conhecida história "O príncipe sapo". Ao ser convidado a viajar na cesta de lanche da princesa, o sapo de Byatt dá esta resposta categórica: "Eu irei, com prazer [...] Mas ela não deve supor que eu me transformarei num belo Príncipe, ou qualquer um desses absurdos. Eu sou um belo Sapo [...] Um belo Sapo é o que devo continuar sendo" (BYATT, 1994, p. 55) ${ }^{11}$. A história, desta vez apresentada a partir da perspectiva do sapo, altera consideravelmente a visão original, colocando em evidência, por exemplo, a irrealidade das transformações mágicas, típicas dos contos de fadas tradicionais.

Além disso, observo que a carga negativa conferida ao sapo no texto tradicional é frontalmente contestada na afirmação "Eu sou um belo Sapo" (1994, p. 55 - grifo meu $)^{12}$. Essa simples colocação subverte ${ }^{13}$ a mensagem embutida no texto original, permitindo que o que se encontrava nas margens do discurso possa agora fazer-se ouvir e ganhe importância. Vale ressaltar que essa voz é diferente e conta-nos uma outra história, trazendo uma faceta ainda não vislumbrada, a questionar o significado convencional. Por meio dessa nova leitura quebra-se a seqüência cristalizada na história tradicional, sugerindo que não é de todo inconcebível que uma nova ordem possa ser instaurada. Como bem observa Joana Passos, "[s]ubverter um conto de fada equivale, de certa forma, a subverter um texto bíblico; quebrando-se a crença, quebra-se a reverência, e abrem-se os horizontes a outras alternativas de organização social e avaliação do mundo" (1996, p. 14). Muitas releituras contemporâneas movemse exatamente nessa direção, possibilitando novos ângulos de visão sobre velhos temas abordados nos contos de fadas.

A escrita paródica é uma outra estratégia narrativa recorrente no revisionismo contemporâneo dos contos de fadas que também pode alterar a forma convencional de lermos as histórias infantis. Sua importância reside no fato de que "através de um processo duplo de instalar e ironizar, a paródia assinala como as atuais representações vêm das anteriores e quais as conseqüências ideológicas derivadas tanto da continuidade quanto da diferença". (HUTCHEON, 1989, p. 93) ${ }^{14}$

Observa-se que estratégias paródicas têm sido freqüentemente utilizadas para contextualizar ironicamente a história e o poder histórico de representações culturais, de modo que tais representações possam ser questionadas e desestabilizadas (HUTCHEON, 1989, p. 102). No caso específico do revisionismo dos contos de fadas, as escritoras evocam personagens ou histórias tradicionais, garantindo a inscrição de novos significados para os textos originais, possibilitando outras leituras não somente dos contos de fadas em questão, mas também da própria cultura que os gerou e consolidou. Assim, concordo com Passos que a escrita paródica é uma espécie de crítica cúmplice que conscientemente tenta deformar aquilo que produz (1996, p. 29). O efeito decorrente é o estranhamento em relação ao real, essencial para o questionamento da cultura e ideologia dominantes. Ao mesmo tempo em que afirma o texto original, a revisão promovida na escrita paródica quebra a estabilidade da interpretação tradicional, alterando as mensagens subliminares cristalizadas pela tradição.

Em "The Bloody Chamber", por exemplo, Angela Carter constrói uma paródia instigadora da famosa lenda do marido assassino - "Barba Azul" - , criando vários contrastes paródicos de efeito revisionista. Em se tratando da questão da culpa e da curiosidade femininas, por exemplo, nessa releitura a história é bem diferente. Ao contextualizar ironicamente a versão de Perrault em "The Bloody Chamber", Carter, entre outras coisas, realça algo não explicitado nas versões consagradas de Barba Azul, ou seja, o papel instigador do marido que, na verdade, seria responsável por 
aguçar a curiosidade das esposas, incitando-as à transgressão. Ainda no que concerne a culpa e a curiosidade femininas, no texto de Carter, de forma diversa do conto original, a desobediência da personagem feminina assume uma conotação visivelmente positiva. Para a protagonista de Carter, o confronto com a realidade material dos crimes do marido, ou seja, a entrada na câmara sangrenta, é indispensável para que a jovem esposa possa reconhecer sua objetificação, sua condição de carne a ser devorada, em sua união matrimonial com o Marquês.

O recurso a estratégias como as que apontei no decorrer da presente discussão tem permitido, entre outras coisas, a exposição dos artifícios dos contos de fadas tradicionais, fazendo com que o revisionismo promova mais do que a mera alteração de nossa visão original dessas narrativas. A revisão, em muitos casos, tem funcionado como um teste ideológico dirigido às interpretações convencionais cristalizadas pela tradição. No entanto, se concordarmos com Nancy A. Walker que o ato revisionista "não é meramente uma ação artística, mas social, sugerindo na prática narrativa a possibilidade de transformação cultural", as releituras só podem ser consideradas politicamente subversivas quando são capazes de "expor ou perturbar os paradigmas de autoridade inerentes nos textos que apropriam"(1995, p. 6-7) ${ }^{15}$. Assim, quando as revisões dos contos de fadas tradicionais buscam minar o contexto discursivo dessas narrativas, provocando importantes rupturas, de modo que as mulheres ganhem voz em contextos nos quais, até então, encontravam-se emudecidas, criam-se condições favoráveis para o surgimento de uma outra história, capaz não somente de contar o que foi previamente apagado, mas também de levar-nos à percepção de que as histórias não precisam continuar sendo como sempre foram.

Diante do que foi exposto, vê-se que esse tipo de trabalho revisionista, que tem sido seriamente abraçado por inúmeras escritoras da atualidade ao relerem clássicos da literatura infantil, é algo promissor e pode vir a constituir-se um ato político de ruptura, de transgressão e de subversão da ordem patriarcal dominante, estabelecida nos textos tradicionais, com a explícita intenção de permitir novas interpretações, novas leituras, que possam de alguma maneira contestar visões distorcidas ou tendenciosas de gêneros sexuais. É bem verdade que precisaremos de tempo para verificar até que ponto esse gesto destemido de inscrever novos significados nos velhos receptáculos das histórias tradicionais, questionando ou subvertendo a chamada "ordem natural das coisas", conseguirá promover a ruptura de nosso modo convencional de conceber a questão de gênero, ampliando nosso horizonte interpretativo no que diz respeito àquelas velhas histórias infantis que acreditávamos conhecer muito bem até então. No entanto, assim como a releitura da história do gênio da lâmpada feita por Byatt nos sugere e a própria história da humanidade comprova, o processo de contar e recontar histórias é pródigo, ou seja, repleto de infinitas possibilidades e impossibilidades.

\footnotetext{
Notas

1

1 No original inglês: "[t]here is a long tradition of instructional literature whose purpose is to tell women how to 'appear' - to make themselves desirable - to men [...] Even fairy tales work to pass on the received collective 'wisdom' of the past and therein reflect the myths of sexuality under patriarchy". Doravante, todas as citações presentes no texto, sejam de textos teóricos ou de ficção, escritos originariamente em inglês, serão traduzidas por mim e terão sua versão original apresentada sob a forma de nota.

2 "There are no eternal myths; they function within a specific historical moment and discursive practice".

3 "we are all part of a universal community with shared values and norms... that a particular type of behavior will produce guaranteed results, like living happily ever after with lots of gold in a marvelous castle, our castle and fortress that will forever protect us from inimical and unpredictable forces of the outside world".
} 


\footnotetext{
4 "Before the woman writer can journey through the looking glass toward literary autonomy [...] she must come to terms with the images on the surface of the glass [...] a woman writer must examine, assimilate, and transcend the extreme images of 'angel' and 'monster' which male authors have generated for her".

5 "in order to reclaim her place in language" / "must play with the tradition that has excluded her, her goal being to reveal, by means of playful repetition, her place both within and outside of the tradition".

6 " the act of looking back, of seeing with fresh eyes, of entering an old text from a new critical direction" / "more than a chapter in cultural history: it is an act of survival".

7 "[a] feminist re-vision makes a historical, cultural and psychic examination of women's cultural past, and creates a woman's history. Rich's concept is close to Michel Foucault's notion of archaelogy-the exposure of moral values encoded in language. Rich took the term from Robert Duncan's The Artist's View (1953). But where Duncan uses "re-vision" merely to describe his own past, Rich's re-vision is a method for all women to share".

8 "an interplay of repetition, imitation and difference".

9 "we need to know the writing of the past, and know it differently than we have ever known it; not to pass on a tradition but to break its hold over us".

10 "disassemble the used components of knowing and knowledge and reassemble them into anti-mythic stories".

11 "I will come gladly ... But she must not suppose I shall turn into a handsome Prince, or any such nonsense. I am a handsome Toad ... A handsome Toad is what I shall remain".

12 "I am a handsome Toad".

${ }^{13}$ Subversão entendida como derrubada do que está deliberado, revolta.

14 "through a double process of installing and ironizing, parody signals how present representations come from past ones and what ideological consequences derive from both continuity and difference".

15 "is not merely an artistic but a social action, suggesting in narrative practice the possibility of cultural transformation" / "to expose or upset the paradigms of authority inherent in the texts they appropriate".
}

\section{Abstract}

In this essay I discuss a type of revisionist writing used by several contemporary women writers as they rewrite or reread traditional fairy tales in a transgressive or subversive way, from a feminist perspective. I also point out some of the narrative strategies employed in such a revisionist process.

Key words: Revision. Fairy tales. Feminist.

Referências

ATWOOD, Margaret. The Robber Bride. Toronto: Seal Books, 1993.

BARTHES, Roland. Mythologies. Trad. Annette Lavers. New York: Hill and Wang, 1972.

BARTHES, Roland. Image Music Text. Trad. Stephen Heath. New York: Hill and Wang, 1977.

BYATT, A. S. The Story of the Eldest Princess. In: The

Djinn in theNightingale's Eye. New York: Vintage, 1994. p. 39-71.

BYATT, A. S. The Djinn in the Nightingale's Eye. In: . The

Djinn in the Nightingale's Eye. New York: Vintage, 1994. p. 93-272.

CARTER, Angela. The Bloody Chamber. In: The Bloody

Chamber and Other Stories. London: Penguin, 1979. p. 7-41.

CARTER, Angela. The Tiger's Bride. In: The Bloody

Chamber and Other Stories. London: Penguin, 1979. p. 51-67. 
CRUNELLE-VANRIGH, Anny. The Logic of the Same and Différance: "The Courtship of Mr.Lyon". In: ROEMER, Danielle M.; BACCHILEGA, Cristina (Ed.). Angela Carter and the Fairy Tale. Detroit: Wayne State University Press, 2001. p. 128-144.

GILBERT, Sandra M.; GUBAR, Susan. The Madwoman in the Attic: The Woman Writer and the Nineteenth-Century Literary Imagination. New Haven: Yale University Press, 1979.

GODARD, Barbara. Feminism and/as Myth: Feminist Literary Theory Between Frye and Barthes in Atlantis: A Women's Studies Journal. Halifax, NS, Canada, v.16, n.2, p. 3-21, spring 1991.

HUMM, Maggie. The Dictionary of Feminist Theory. Columbus: Ohio State University Press, 1999.

HUTCHEON, Linda. The Politics of Postmodernism. London: Routledge, 1989.

LAPPAS, Catherine. Rewriting Fairy Tales: Transformation as Feminist Practice in the Nineteenth and twentieth Centuries.1995. $169 \mathrm{f}$. Tese (Doutorado). University of Western Ontario, 1995.

PASSOS, Joana Filipa da Silva de Melo Vilela. Angela Carter e a Reescrita de Mitos e Contos de Fadas. 1996. 137 f. Dissertação (Mestrado em Língua e Literaturas Inglesas). Universidade do Minho, Braga. 1996.

RICH, Adrienne. When We Dead Awaken: Writing as Re-vision In: GILBERT, Sandra M.; GUBAR, Susan (Eds.) The Norton Anthology of Literature by Women: The Tradition in English. New York: W.W. Norton, 1985. p. 2044-2056.

WALKER, Nancy A. The Disobedient Writer: Women and Narrative Tradition. Austin: University of Texas Press, 1995.

ZIPES, Jack. The Brothers Grimm: From Enchanted Forests to the Modern World. New York: Routledge, 1988. 